

\section{Sumário}

UMA PERSPECTIVA COMPARADA ACERCA DA (NÃO) EFETIVIDADE DA DEMOCRACIA LOCAL NO BRASIL E EM Portugal. .................................................................................................... 12 Matheus Passos Silva

A “ATIVIDADE-AÇÃO” PUNITIVO-DISCIPLINAR. INTERATIVIDADE E COMPLEXIDADE ENTRE ATO, PROCEDIMENTO E PROCESSO ADMINISTRATIVO

Sandro Lucio Dezan e Paulo Afonso Cavichioli Carmona

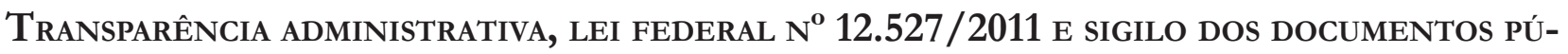
Blicos: A inconstitucionalidade dAS RESTRições AO ACESSO À INFORMAÇÃo....................46 Emerson Affonso da Costa Moura

A influência do Direito Administrativo Global no processo brasileiro de ContrataÇão Pública à luz do Princípio da Transparência .66 Alice Rocha da Silva e Ruth Maria Pereira dos Santos

Interna Corporis Acta e os limites do controle Judicial dos Atos legislativos..........90 Cintia Garabini Lages

A Releitura do PRINCíPIO dA ACTIO NATA QUANTO AOS DiREITOS DifUSOS NA JUDiCIALIZAÇÃo BRASILEIRA 105 Luiz Gustavo Gonçalves Ribeiro e Lorena Machado Rogedo Bastianetto

A Defensoria pública como garantia constitucional Processual de aCESSo À JustiÇa Na AMÉrica do Sul 117 Antonio Henrique Graciano Suxberger e Alberto Carvalho Amaral 
A política de assistênCia social e a promoção ao trabalho: uma ANÁlise do PRONATEC BSM COM BASE EM UM ESTUdo COM EgRESSOS EM ForTALEZA-CE

Aline de Araújo Araújo Martins e Mônica Duarte Cavaignac

INTERVENÇÃo ESTATAL NA AGRICULTURA: A POSSIBILIDADE DE UMA AÇão ÉTICA A FIM DE MATERIALIZAR A CONSTITUIÇÃO BRASILEIRA............................................................ 164

Davi Augusto Santana de Lelis e Giovani Clark

Agricultura orgânica: SOlUÇão Para o SÉCulo XXI? 185

Eloir Trindade Vasques Vieira, Denilson de Oliveira Guilherme, Luis Carlos Vinhas Itavo e Lucelia da Costa Nogueira Tashima

Os DESAFIos JURÍdicos E ECONÔMICOS DA AVIAÇão REgIONAL NO BRASIL

Pablo Leurquin e Mariana Magalhães Avelar

Homeschooling No Brasil: CONFORMAÇÃo DEÔNTICO-AXIOLÓGICA do SISTEMA JURÍdico COMO PLUS À POLÍTICA PÚBLICA DE EDUCAÇÃO FUNDAMENTAL.

Cláudio Márcio Bernardes, Giovani Clark

BARREIRAS À CIDADANIA NAS POlítiCAS SOCIAIS PARA A POPULAÇão EM SITUAÇÃo DE RUA........237 Luciano Roberto Gulart Cabral Júnior e José Ricardo Caetano Costa

O CORTE DO FORNECIMENTO DE ÁGUA EM FACE DO INADIMPLEMENTO DO CONSUMIDOR: ANÁLISE À LUZ DO DiÁlOGO DAS FonTES 251 Leonardo Roscoe Bessa e Gabriela Gomes Acioli César

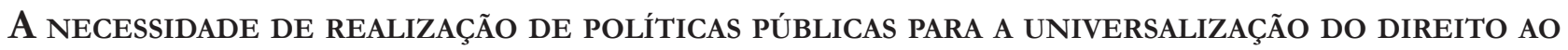
SANEAMENTO BÁSICO

Ruth Santos e Renata Menezes 


\title{
O corte do fornecimento de água em face do inadimplemento do consumidor: análise à luz do Diálogo das Fontes*
}

\author{
The cutting of water supply due to consumer \\ default in payment: an analysis through the \\ dialogue of sources.
}

\author{
Leonardo Roscoe Bessa** \\ Gabriela Gomes Acioli César***
}

\section{Resumo}

$\mathrm{O}$ artigo trata da legalidade da suspensão de fornecimento de água ao consumidor quando inexiste o pagamento do serviço. A questão é analisada com enfoque em diferentes diplomas legais, principalmente em relação ao Código de Defesa do Consumidor (Lei 8.078/90) e à Lei de Concessão e Permissão de Serviços Públicos (Lei 8.987/95). Propõe-se solução com base no diálogo das fontes, com especial releve para a cláusula constitucional de proteção da dignidade da pessoa humana.

Palavras-Chave: Água. Serviço público. Bem essencial. Corte. Inadimplemento do consumidor. Diálogo das Fontes. Dignidade da pessoa humana.

\section{Abstract}

The article deals with the legality of water supply suspension when consumers' payment does not occur. The analyzes is focused on different legislation, particularly in relation to the Brazilian Consumer Protection Code (Law 8.078 / 90) and the Law of Concession and Permission of Public Services (Law 8.987 / 95). A solution is proposed based on the dialogue of sources, with particular attention to the constitutional provision of human dignity protection.

* Recebido em 18/12/2015

Aprovado em 22/08/2016

** Professor de graduação e do Programa de Mestrado e Doutorado do UNICEUB. Mestre em Direito Público pela Universidade de Brasília - UnB, Doutor em Direito Civil pela UERJ. Procurador-Geral de Justiça do Distrito Federal (MPDFT 2014/2016). E-mail: rosce@mpdft. mp.br.

*** Graduada em Direito pelo Centro Universitário de Brasília - UniCEUB e pós-graduada em Direito do Trabalho e Processo do Trabalho pela Universidade Anhanguera - UNIDERP. Servidora do Tribunal de Justiça do Distrito Federal e dos Territórios - TJDFT. E-mail: gabyacioli86@hotmail.com.
Keywords: Water. Public service. Essential good. Court. Consumer default. Dialogue of sources. Human dignity.

\section{INTRODUÇÃo}

O presente artigo aborda a possibilidade jurídica de interrupção do fornecimento de água em face do inadimplemento do consumidor. Embora o tema já tenha sido objeto de inúmeros acórdãos e atenção da doutrina, observa-se que as posições são antagônicas e injustificadamente extremadas, ora permitindo, ora vedando o corte do fornecimento, sem atentar para a possibilidade de, a partir de diálogo das fontes, prestigiar ambas alternativas. 
Com o propósito de demonstrar a necessidade de exame mais cauteloso dos casos que se apresentam no âmbito administrativo e jurisdicional, o presente artigo, em um primeiro momento, destaca a essencialidade da água para a vida e dignidade da pessoa humana. Em seguida, delineia-se panorama normativo do tema para evidenciar, de um lado, a extrema relevância do serviço público e, de outro, a necessidade de contribuição pecuniária de todos para funcionamento adequado e permanente do sistema de abastecimento de água.

Em relação à problematização do tema, demonstra-se a multiplicidade de posições doutrinárias, bem como as divergências no âmbito do Superior Tribunal de Justiça, órgão do Poder Judiciário que possui competência constitucional para definição final da interpretação que deve prevalecer.

Apresenta-se o diálogo das fontes como caminho possível para análise da contradição - aparente - entre os diplomas legais que regem o serviço, destacando a necessidade de exame detido para verificar, no caso concreto, a consequência da interrupção de fornecimento da água, principalmente no que concerne ao desrespeito da cláusula constitucional de proteção da dignidade da pessoa humana (CF, art. $1^{\circ}$, III).

\section{A essencialidade da Água}

A importância da água é uma constante histórica. Na visão mitológica, a água trazia consigo as sementes da vida, além dos medos que corriqueiramente eram evocados pelas figuras míticas dela oriundas ${ }^{1}$. O homem, percebendo a importância desse bem natural, tanto para sua mantença quanto para o desenvolvimento de suas atividades, foi, ao longo do curso da história, aprimorando formas de captação e de gerenciamento da água.

$\mathrm{Na}$ Antiguidade, os fenômenos naturais tinham uma conotação bastante mística vinculada à simbologia religiosa que imperava nas sociedades daquele tempo. A água era considerada a origem da vida e, consequentemente, motivo de devoção para muitas culturas. Povos como os Gregos, Romanos, Egípcios e Mesopotâmios construíram verdadeiros impérios hidráulicos com a finalidade de gerir esse recurso para o desenvolvimento de suas civilizações e para a sobrevivência das sociedades. Entretanto, as técnicas destinadas à administração das águas ainda eram incipientes para que o acesso fosse garantido a todos. Ao longo do tempo, surgiram muitas doenças e epidemias decorrentes da falta de acesso à água tratada. ${ }^{2}$

A situação de escassez e até mesmo de regime de recessão se dava pelo fato de que os grandes líderes de civilizações, como a Egípcia, se utilizavam da sacralidade que envolvia as criaturas da natureza, para subjugar os povos e manter o controle sobre os súditos ${ }^{3}$. Ora, sem água, não se pode viver, portanto, aquele que mantinha a gestão desse bem era visto como poderoso e, nesse caso, divino, tendo em vista toda a religiosidade impregnada dos povos teocráticos.

Com as epidemias, percebeu-se a vinculação existente entre a necessidade de saneamento, abastecimento de água e o devido tratamento à saúde das pessoas. A evolução tecnológica científica, ocorrida na passagem da Idade Média para o Renascimento, permitiu uma mudança de visão, retirando da água esse aspecto eminentemente sacramental ${ }^{4}$, como também de mera utilização para o fomento das atividades agrícolas e direcionando para a questão da saúde pública, adotando, assim, medidas técnicas e sanitárias com o intuito de estancar o mal que assolava as civilizações: o surto epidêmico.

1 SILVA, Elmo Rodrigues da. XI-009 - Um percurso pela história através da água: passado, presente, futuro. Disponível em: < http://www.bvsde.paho.org/bvsaidis/saneab/xi-009.pdf >. Acesso em: 21 jan. 2016.

2 Ibidem.

3 SILVA, Elmo Rodrigues da. XI-009 - Um percurso pela história através da água: passado, presente, futuro. Disponível em: <www.bvsde.paho.org/bvsaidis/saneab/xi-009.pdf>. Acesso em: 21 jan. 2016.

4 A sacralidade da natureza ocorre através do que se denomina 'freios homeostáticos', os quais seriam códigos legislativos empíricos, de fundo religioso, análogos aos princípios ecológicos que regulam o equilíbrio das relações naturais. Pode-se dizer que os 'freios homeostáticos mentais' seriam produzidos pelas normas de comportamento vinculadas às tradições e aos costumes, as quais se manifestam através dos rituais míticos que dão à natureza o seu caráter sagrado. 
A situação se agravou na transição entre o período medieval e o período moderno devido às contínuas guerras, fazendo com que fossem construídas nas cidades fortificações com escavações de fossos canalizados em que as águas ficavam paradas e se tornavam propulsoras de inúmeras doenças. ${ }^{5}$

Com a modernidade e a mudança de paradigmas, os governos europeus tiveram uma maior preocupação com o controle na gestão da água e com o aumento da distribuição desse bem, partindo-se para uma busca de modelo de saneamento adequado a ser implantado.

No que tange à epidemiologia, as descobertas da medicina no século XIX e início do século XX levaram a administração pública a prover uma revolução no campo estrutural das cidades, com o fito de erradicar a insalubridade existente por meio da construção de redes de água canalizadas, voltando sua política para a saúde da coletividade. ${ }^{6}$

Portanto, como se pode perceber, o acesso à água é intrínseco à garantia de uma vida saudável e com dignidade. Estipular medidas que deixem de fora do abastecimento de água uma parcela da população, principalmente aqueles que não podem pagar por seu tratamento e fornecimento, é fomentar a busca por medidas alternativas, como assim fizeram os povos em outras épocas. Isto se torna perigoso e, a longo prazo, dispendioso para o próprio Estado, o qual arcará, inevitavelmente, com custos maiores na área da saúde pública, posto que as consequências possíveis e previsíveis são o alastramento de doenças e epidemias.

Acrescenta-se a isso, em julho de 2014, a crise da água tomou conta do país, a começar por São Paulo. Com o esvaziamento do reservatório Cantareira e as previsões de falta de chuva, a cidade enfrentou a maior crise hídrica dos últimos 80 anos.

A urbanização, que aumenta a poluição dos rios e dificulta o acesso à água potável, associada a vários outros fatores já conhecidos, como a verticalização, a impermeabilização do solo, a falta de planejamento e a sobrecarga do sistema de abastecimento e coleta, contribuiu para a instalação da crise atual. Além disso, a água, que chega até a torneira, passa por tubulações construídas em 1940 ou 1950. Ou seja, um sistema defasado, o que facilita o desperdício. A cada segundo, mais de 1200 litros são jogados fora no processo de distribuição. Com toda a água desperdiçada no país ao longo de um dia, daria para abastecer 932 milhões de pessoas (ou três vezes a população dos EUA). Isso porque explora-se pouco e mal os recursos hídricos aqui existentes.

\section{O fornecimento de Água COMO deVER do Estado}

A água foi consagrada como bem de domínio público na Lei n. 9.433/97, que instituiu a Política Nacional de Recursos Hídricos. O seu fornecimento é de responsabilidade do Poder Público, justamente pelo seu caráter de essencialidade. A Lei de Greve (Lei n. 7.783/89) estabelece, expressamente, que o serviço de abastecimento de água é essencial (art. 10, I).

Este diploma legal reconhece o que a experiência histórica indica. A essencialidade diz respeito à necessidade do ser humano, garantindo, assim, sua saúde, segurança, bem-estar e a vida com dignidade, elemento fundamental para estabelecer quais serviços devem ser prestados pelo Poder Público.

A água, apesar de compor mais de 70\% do planeta, tem como porcentagem servível para consumo menos de $1 \%{ }^{8}$. Com a evolução e o crescimento da população, esse bem da natureza torna-se cada vez mais es-

5 Ibidem.

6 SILVA, Elmo Rodrigues da. XI-009 - Um percurso pela história através da água: passado, presente, futuro. Disponível em: <www.bvsde.paho.org/bvsaidis/saneab/xi-009.pdf>. Acesso em: 21 jan. 2016.

7 VILAVERDE, Carolina, MUNIZ BAPTISTA, Lucas, SOARES, Jessica e SODRÉ, Raquel. O Fundo do Poço. Disponível em: $<$ http://super.abril.com.br/crise-agua/ofundodopoco.shtml>. Acesso em: 05 mai. 2015.

8 UNIVERSIDADE DA ÁGUA. Água no planeta. Disponível em: <http://www.uniagua.org.br/publichtml/website/default. 
casso e o seu consumo precisa ser equilibrado, gerido de forma a garantir a saúde da sociedade no presente, mas com vistas para a geração futura. Por esse motivo, também constitui dever do Estado se responsabilizar por sua gestão, tratamento e distribuição de maneira equitativa e sustentável.

O seu fornecimento não está atrelado, apenas, à dignidade da pessoa humana (em ótica individual), mas também à tutela do Estado no que tange à saúde coletiva, posto ser pressuposto fundamental e dever do Poder Público promover políticas públicas de controle da saúde pública. Sabe-se que os gastos são menores em se tratando de investimento em saneamento básico do que na resolução dos problemas advindos da precariedade e má higienização da sociedade. De acordo com a Lei n. 8.080, de 19 de setembro de 1990, que dispõe sobre as ações e serviços de saúde, o saneamento básico, que inclui o fornecimento de água tratada para consumo, constitui fator determinante para promoção, proteção e recuperação da saúde $\left(\operatorname{art.} 3^{\circ}\right)$.

Esse caráter essencial do fornecimento de água traz consigo outras perspectivas, quais sejam: o direito de acesso a esse serviço deve ser garantido a todas as pessoas em igualdade de condições, ou seja, todos devem poder usufruir do serviço adequadamente, sem distinção de qualquer ordem, principalmente a econômica, bem como a questão da continuidade do serviço, que será abordada mais adiante.

Como visto, a titularidade da prestação do serviço público essencial de fornecimento de água é do Poder Público, em que pese representado pelos três entes federativos que decidirão de acordo com a realidade de cada um e conforme as peculiaridades de cada região. $\mathrm{O}$ art. 175 da Constituição Federal estabelece que a prestação de serviços públicos é de responsabilidade do Poder Público, direta ou indiretamente sob regime de concessão ou permissão, nesses casos, sempre, feito por licitação, em conformidade com a lei.

Devido ao caráter e a especificidade do bem a ser prestado, o Poder Público manteve, por muito tempo, o monopólio do fornecimento sob os seus cuidados, até pela íntima relação do serviço com a saúde da coletividade, com o fito de não transferir para particulares uma atividade que não deve, sob hipótese alguma, se submeter ao alvedrio de empresas que funcionam com finalidade lucrativa e respondendo às leis egoísticas de mercado.

Todavia, a política desenvolvimentista, a globalização e as pressões dos grupos econômicos externos, no sentido de o Brasil desempenhar de maneira satisfatória e rentável o desenvolvimento de suas atividades, cumprindo os compromissos assumidos no âmbito internacional, foram impulsionadores do Estado brasileiro no que diz respeito ao início da prestação dos serviços públicos por meio de terceiros que passaram a executar as tarefas, antes de incumbência, apenas, do Poder Público centralizador, por meio de delegação.

Juridicamente, esse instituto foi previsto na Constituição da República como um dos instrumentos de descentralização do Estado. Assim, o Poder Público possui a incumbência de prestar os serviços públicos diretamente (por seus órgãos e agentes) ou, indiretamente, por meio de concessão ou permissão.

Em 1995, o legislador ordinário cumpriu o determinado pelo art. 175 da Constituição Federal e promulgou, em 13 de fevereiro, a Lei n. 8.987 que trata do regime de Concessão e Permissão no serviço público. Dentre muitos conceitos, a lei estabeleceu uma série de princípios que devem nortear a prestação dos serviços públicos fornecidos direta e indiretamente. Ressalte-se que, tanto os que sejam diretamente prestados pela Administração quanto os que forem fornecidos por particulares, principalmente estes, precisam observá-los no desempenho e qualificação de suas atividades.

Entre os princípios elencados na lei - regularidade, eficiência, segurança, atualidade, generalidade, cortesia, modicidade das tarifas -, recebe destaque para o presente estudo o que trata da continuidade dos serviços. Cabe destacar, todavia, que a própria lei prevê hipóteses nas quais o serviço pode sofrer solução de continuidade: uma delas é justamente quando o usuário deixa de realizar o pagamento pecuniário pelo serviço $\left(\operatorname{art.~} 6^{\circ}, \S 3^{\circ}, \mathrm{II}\right)$.

asp?tp=3\&pag=aguaplaneta.htm $>$. Acesso em: 17 mai. 2015. 
O capítulo da Constituição Federal em que está inserido o instituto da concessão dos serviços públicos é o que dispõe sobre a ordem econômica e financeira. Por essa razão, se faz necessário respeitar os princípios elencados no início da Carta, como também os listados no art. 170, cuja disposição é no sentido de que a ordem econômica na consecução de suas atribuições precisa garantir a todos uma existência digna, assegurada, no inciso $\mathrm{V}$, a defesa do consumidor (v. item seguinte).

\section{Código de Defesa do Consumidor e a proteção conferida a serviços públicos ESSENCIAIS}

O fundamento da proteção do consumidor pelo Estado é sua vulnerabilidade - fragilidade - no mercado do consumo. Ao contrário do que propugnava a Teoria Econômica Clássica, as reais necessidades do consumidor não foram, nem são, tão preponderantes para definição da estrutura e objetivos dos integrantes da cadeia de produção e comercialização de bens e serviços. "Hoje, os economistas reconhecem que a realidade primária, a ser levada em consideração, na análise do mercado, não são as necessidades individuais dos consumidores e sim o poder econômico dos organismos produtores, públicos ou privados."

O consumidor está, sob diversos enfoques, em visível situação de fragilidade - vulnerabilidade - no mercado de consumo, não apenas - ressalte-se - em relação a interesses patrimoniais, mas também, e com maior intensidade, em seus interesses existenciais (projeções da dignidade humana).

Historicamente, tal fragilidade intensificou-se na mesma proporção do processo de industrialização e massificação das relações no mercado de consumo, ocorrido, particularmente, nas décadas posteriores ao término da Segunda Guerra Mundial. Ante essa constatação, diversos países, principalmente a partir da década de 70 , editaram normas de tutela dos interesses dos consumidores. ${ }^{10}$

No Brasil, a Constituição de 1988 referiu-se à proteção jurídica do consumidor em três oportunidades. A defesa do consumidor pelo Estado inclui-se entre os direitos e garantias fundamentais (art. $5^{\circ}$, XXXII). Em outro tópico, como um dos princípios gerais da atividade econômica, indicou-se a proteção dos interesses do consumidor (art. 170, V). Ademais, nos termos do art. 48 das Disposições Constitucionais Transitórias, restou estabelecido que o Congresso Nacional deveria, em prazo máximo de 120 dias, após a promulgação da Constituição, elaborar um código de defesa do consumidor.

Ainda sob perspectiva constitucional, a dignidade da pessoa humana, fundamento expresso da República Federativa do Brasil (art. $1^{\circ}$, III, da CF), justifica a tutela da pessoa humana no mercado de consumo. De fato, "a proteção do consumidor deve ser estudada como momento particular e essencial de uma tutela mais ampla: aquela da personalidade humana."

9 Fábio Konder Comparato. A proteção do consumidor: importante capítulo do Direito econômico. Revista Forense, v. 255, ano 72, jul-set, Rio de Janeiro, 1976, p. 19. Sobre a vulnerabilidade do consumidor no mercado de consumo, v. BESSA, Leonardo Roscoe. Relação de Consumo e Aplicação do Código de Defesa do Consumidor. 2 ed. São Paulo: Revista dos Tribunais, 2009 , p. $27-46$

10 Cite-se, apenas a título de exemplo, a Lei alemã de 09/12/1976, conhecida como AGB-Geseť, sobre condições gerais dos contratos, Lei francesa de 22.12.72 relativa à venda a domicílio, e o Fair Credit Reporting Act de 1970, que, ainda hoje, disciplina os bancos de dados de proteção ao crédito nos Estados Unidos.

11 Gustavo Tepedino, o qual, sustenta, com absoluta propriedade, que o art. $5^{\circ}$, XXXII, art. 170, V, devem ser analisados em conjunto com o disposto no art. $1^{\circ}$, III e $3^{\circ}$, III, da Constituição Federal: “O Constituinte, assim procedendo, não somente inseriu a tutela dos consumidores entre os direitos e garantias individuais, mas afirma que sua proteção deve ser feita do ponto de visa instrumental, ou seja, com a instrumentalização dos seus interesses patrimoniais à tutela de sua dignidade e aos valores existenciais. Trata-se, portanto, do ponto de vista normativo, de proteger a pessoa humana nas relações de consumo, não já o consumidor com uma categoria per se considerada." A responsabilidade civil por acidentes de consumo na ótica Civil-constitucional, in Temas de Direito Civil, Rio de Janeiro, Renovar, p. 279-281. Outros autores têm destacado a importância de análise do Código de Defesa do Consumidor a partir de perspectiva constitucional e com especial destaque para o princípio da dignidade da pessoa humana. 
O mercado de consumo, principalmente em face de sua conformação massificada, enseja, em diversos aspectos, ofensa à dignidade da pessoa humana, tanto pelos inúmeros acidentes de consumo (com ofensa à integridade psicofísica do consumidor), publicidades abusivas, controle de dados pessoais do consumidor (perda da privacidade), cobrança abusiva de débito, quanto - ressalte-se - pela negação de serviços públicos essenciais como o fornecimento de água.

Em 11 de setembro de 1990, editou-se a Lei Federal n. 8.078 (Código de Defesa do Consumidor), a qual dispõe sobre "normas de proteção e defesa do consumidor, de ordem pública e interesse social" (art. 1"). ${ }^{12}$ Considerando-se os propósitos do artigo, destacam-se os dispositivos que se aplicam aos serviços públicos.

$\mathrm{O}$ art. $3^{\circ}$, caput estabelece o conceito de fornecedor, enquadrando, também, o Poder Público quando afirma ser "toda pessoa física ou jurídica, pública ou privada" que disponibilize produtos ou serviços no mercado de consumo. Além disso, o parágrafo $2^{\circ}$ do mesmo artigo aponta, de forma ampla, o serviço que será objeto de uma relação de consumo, inseridos os públicos. Mais à frente, no artigo $4^{\circ}$, ao elencar os objetivos da Política Nacional das Relações de Consumo, tutela o atendimento das necessidades dos consumidores tomando como mecanismo para se chegar a esse objetivo o princípio da racionalização e melhoria dos serviços públicos.

Acrescente-se que, entre os direitos básicos do consumidor, está a adequada e eficaz prestação dos serviços públicos em geral (art. $6^{\circ}, \mathrm{X}$ ). Para encerrar o panorama normativo do Código de Defesa do Consumidor, em relação ao tema, o art. 22 dispõe que "os órgãos públicos, por si ou por suas empresas, concessionárias, permissionárias ou sob qualquer outra forma de empreendimento, são obrigados a fornecer serviços adequados, eficientes, seguros e, quanto aos essenciais, contínuos".

Diante do quadro apresentado, chega-se ao problema a ser enfrentado neste artigo. Como resolver a contradição - ao menos aparente - do ordenamento jurídico no tocante ao abastecimento individual de água quando há solução de continuidade no pagamento por parte do usuário. De um lado, considera-se o fornecimento de água serviço essencial e que, portanto, não pode ser interrompido (Lei de Greve e Código de Defesa do Consumidor, Leis n. 7.783/89 e 8.078/90, respectivamente). De outro, admite-se a suspensão do fornecimento em face de inadimplemento do consumidor (Lei n. 8.987/97, art. $6^{\circ}$, $\ 3^{\circ}$, II). Qual norma deve prevalecer? A questão deve ser resolvida pelos critérios tradicionais de conflito de leis no tempo?

Propõe-se, como desenvolvido na sequência, a necessidade de realizar diálogo das fontes para obtenção das respostas possíveis.

\section{Diálogo dAS FonTES}

Em todo e qualquer debate relativo à aplicação do Código de Defesa do Consumidor, é fundamental perceber que a incidência do diploma de proteção ao consumidor a determinado suporte fático não afasta, além de perspectiva constitucional (dignidade da pessoa humana), análise simultânea e harmoniosa com outras fontes legais.

12 O CDC inspirou-se em importantes modelos legislativos de outros países. A maior influência veio do Projet de Code de la Consommation. Os direitos básicos do consumidor foram extraídos da Resolução 39/248, da ONU. Merecem referência, também, a Lei General para la Defensa de los Consumidores y Usuários da Espanha (Lei 26/1984), a Lei 29/81, de Portugal, a Lei Federal de Protección ao Consumidor, de 05 de fevereiro de 1976, do México e a Loi sur la Protection du Consommateur, promulgada em 1979, no Quebec.Em relação a matérias específicas, houve inspiração no Direito Comunitário europeu: Diretivas 84/450 (publicidade) e 85/374 (responsabilidade civil pelos acidentes de consumo). Concernente à proteção contratual do consumidor, citem-se o Decreto-lei 446/85 de Portugal e a Gesetz zur Regelung des Rechts des Allgemeinen Geschaftsbedingungen - AGB Gesetz, de dezembro de 1976, da Alemanha. A influência do direito norte-americano decorreu diretamente do Federal Trade Comission Act, do Consumer Product Safety Act, do Truth in Lending Act, do Fair Credit Reporting Act e do Fair Debt Collection Practices Act. Registre-se, ainda, influência indireta na medida em que as regras européias mais modernas de proteção ao consumidor inspiraramse nos cases e estatutes americanos. 
A velocidade dos fatos tem conduzido a uma inflação de leis específicas nas mais diversas áreas. A Constituição Federal, em razão de sua superioridade hierárquica e da complexidade cada vez maior do ordenamento jurídico, ganha missão - principalmente pelas mãos dos intérpretes - de conferir coerência a essa multiplicidade de fontes normativas.

Nessa linha, Pietro Perlingieri destaca a importância da Constituição Federal como unificadora de valores do ordenamento jurídico, o qual tem sido representado por um número crescente de fontes legislativas fragmentadas. Ressalta o jurista italiano que "numerosas leis especiais têm disciplinado, embora de modo fragmentado e por vezes incoerente, setores relevantes" e que a perda de centralidade do Código Civil no séc. XX transfere o papel unificador do sistema para a Constituição, a qual passa a estabelecer um desenho global para unir as mais variadas fontes legais. ${ }^{13} \mathrm{Com}$ base nessa perspectiva constitucional, há que se buscar uma convivência harmônica entre diversas fontes legais.

O Código de Defesa do Consumidor (Lei n. 8.078/90), em razão do corte horizontal nas mais diversas relações jurídicas, é significativo exemplo da necessidade atual de convivência com diversos outros diplomas. A par da necessária utilização de base conceitual do Código Civil, o art. $7^{\circ}$, caput, ${ }^{14}$ do CDC é expresso no sentido de que não é exclusividade dele estabelecer os direitos do consumidor. Outras normas podem, especialmente quando mais vantajosas ao consumidor, ser invocadas e aplicadas e, inevitavelmente, analisadas em conjunto, buscando-se, sempre, coerência e harmonia nas conclusões.

O Código de Defesa do Consumidor é, em relação ao Código Civil, norma especial que considera, preponderantemente, a vulnerabilidade do consumidor no mercado. É, em regra, norma especial quanto ao sujeito. Sua incidência, entretanto, não afasta, a priori, a aplicação de outras normas especiais. O serviço de fornecimento de água bem exemplifica a crescente edição de leis especiais - em relação à matéria - que convivem com esse diploma legal.

Reitere-se a necessidade da perspectiva constitucional apontada: na análise simultânea de diversas normas do mesmo nível hierárquico, deve o intérprete, em ponderação de bens, conferir eficácia aos princípios, valores e direitos garantidos constitucionalmente. ${ }^{15}$

Hoje, a tarefa do intérprete e aplicador do direito de hoje é bem mais complexa e dinâmica, requer exame concomitante de diversos atos normativos em que pouca utilidade terão os critérios tradicionais de solução de conflitos (antinomia) de leis, estabelecidos na Lei de Introdução às Normas do Direito Brasileiro. ${ }^{16}$ A propósito, Cláudia Lima Marques, baseando-se em Erik Jayme, ressalta a necessidade de haver o que, sugestivamente, denomina diálogo das fontes: "Aqui a preocupação do direito é a legitimidade da solução, pois todas as normas em conflito são 'válidas' e devem ter alguma eficácia, mesmo que auxiliar. O diálogo das fontes é, pois, a aplicação simultânea, compatibilizadora, das normas em conflito, sob a luz da Constituição, com efeito útil para todas as leis envolvidas, mas com eficácias (brilhos) diferenciadas a cada uma das normas em colisão, de forma a atingir o efeito social (e constitucional) esperado. O 'brilho' maior será da norma que concretizar os direitos humanos envolvidos no conflito, mas todas as leis envolvidas participarão da solução concorrentemente."17

Em outra sede, a autora esclarece: "Em seu curso Geral de Haia, de 1995, o mestre de Heidelberg, Erik Jayme, ensinava que, em face do atual ‘pluralismo pós-moderno’ de um Direito com fontes legislativas plúri-

13 Perfis do direito civil: introdução ao direito civil constitucional. 2. ed., Rio de Janeiro: Renovar, 2002, p. 04-06.

14 Art. 7. ${ }^{\circ}$, caput, do CDC: "Os direitos previstos nesse código não excluem outros decorrentes de tratados ou convenções internacionais de que o Brasil seja signatário, da legislação interna ordinária, de regulamentos expedidos pelas autoridades administrativas competentes, bem como dos que derivem dos princípios gerais do direito, analogia, costumes e equidade."

15 Sobre ponderação de valores constitucionais, v., por todos, A nova interpretação constitucional: ponderação, direitos fundamentais e relações privadas. (Org.: Luis Roberto Barroso), Rio de Janeiro: Renovar, 2003.

16 O Dec-lei 5.657/42 estabelece que as leis gerais não revogam as especiais e não são revogadas por elas (art. $2^{\circ}$ ). A dificuldade, entretanto, reside em definir o que é geral e especial e, invariavelmente, harmonizar a existência de duas leis especiais, uma em relação aos sujeitos da relação (consumidor e fornecedor) e outra em relação ao objeto (plano de saúde, por exemplo).

17 Contratos no Código de Defesa do Consumidor. 5 ed. São Paulo: Revista dos Tribunais, 2011, p. 611-613. 
mas, ressurge a necessidade de coordenação entre as leis no mesmo ordenamento, como exigência para um sistema eficiente e justo. Efetivamente, cada vez mais se legisla, nacional e, internacionalmente, sobre temas convergentes. A pluralidade de leis é o primeiro desafio do aplicador da lei contemporâneo." ${ }^{18}$

Diante desse quadro, é absolutamente insuficiente sustentar que, por existir lei especial disciplinando determinado setor, afasta-se a aplicação do Código de Defesa do Consumidor (Lei n. 8.078/90). Deve-se, ao contrário, buscar o convívio harmônico dos variados diplomas legais: um auxiliando e oferecendo elementos de interpretação para o outro, sempre, destaque-se, sob as luzes dos princípios e valores constitucionais. Antes de afastar a aplicação de uma das fontes, deve-se buscar a possibilidade de interpretação coerente entre as diversas fontes. É o que se pretende fazer para análise da polêmica relativa ao corte do fornecimento de água em face de inadimplemento do consumidor.

\subsection{O diálogo das fontes como solução}

Antes de melhor explicitar o diálogo das fontes como caminho adequado para análise da questão, importante fazer breve revisão bibliográfica para apontar como são díspares as posições doutrinárias sobre a possibilidade de corte do fornecimento de água em face da inadimplência do consumidor.

Zelmo Denari sustenta a legalidade de corte em razão do inadimplemento, mas destaca que "a interrupção no fornecimento do serviço público não pode ser efetivada ex abrupto, como instrumento de pressão contra o consumidor, para forçá-lo ao pagamento da conta em atraso." ${ }^{19}$ Acrescenta que, se o usuário for pessoa jurídica de direito público, "a interrupção é inadmissível, porque, além de estar em causa o interesse público - cuja supremacia é indiscutível em termos principiológicos -, o ente público pode invocar, em sentido diametralmente oposto, o postulado dos serviços que presta à população em geral."20

Fabio Amorim da Rocha defende a relativização do princípio da continuidade. Para o autor é inteiramente eficaz e válida a disposição normativa que estabelece não figurar descontinuidade do serviço a interrupção nos casos emergenciais ou, após prévio aviso, por razões de ordem técnica ou de segurança, bem como por inadimplência do usuário, levando em conta o interesse da coletividade (art. $6^{\circ}$, $\int 3^{\circ}$, I e II da Lei n. $8.978 / 95) .^{21}$

Fernando Costa de Azevedo propugna não aplicar o disposto na norma autorizadora da suspensão nos casos de inadimplência consiste em fomentar o enriquecimento sem causa por parte de muitos usuários-consumidores, os quais, de má-fé, se aproveitam do princípio destinado à proteção dos seus interesses. Dessa maneira, tornar-se-ia inviável a manutenção do serviço, tendo em vista que, sem o retorno de todos os usuários, não existiria suporte financeiro suficiente para a melhoria e até mesmo universalização do serviço. Haveria um desequilíbrio financeiro e, também, uma maior oneração para os usuários-consumidores adimplentes, que, por sua vez, arcariam com os custos do serviço. ${ }^{22}$

Para Alessandro Segalla, no que tange, principalmente, ao fornecimento de água, há necessidade de se ter uma visão mais ampla no sentido de que a prestação desse serviço é pautada no interesse público e não apenas no âmbito privado do usuário-consumidor, pois, segundo ele, a instalação de rede de distribuição de água tratada e de coleta de esgotos não se faz como de satisfação do interesse individual dos usuários.

18 DENARI, Zelmo, Diálogo entre o Código de Defesa do Consumidor e o novo Código Civil: do "diálogo das fontes" no combate às cláusulas abusivas, Revista de Direito do Consumidor, São Paulo, n. 45, jan./mar., 2003. p. 71-72.

19 Código de Defesa do Consumidor comentado pelos autores do anteprojeto, cit., p. 216.

20 Ibid., p. 216.

21 ROCHA, Fábio Amorim da. A legalidade da suspensão do fornecimento de energia elétrica aos consumidores inadimplentes. Rio de Janeiro: Lumen Juris, 2004, p. 30-33.

22 AZEVEDO, Fernando Costa de. A suspensão do fornecimento de serviço público essencial por inadimplemento do consumidor-usuário: argumentos doutrinários e entendimento jurisprudencial. Revista do Direito do Consumidor, v. 16, n. 62, abr./jun. 2007, São Paulo: Revista dos Tribunais, p. 99-101. 
Trata-se de instrumento de saúde pública. Por meio desses serviços, eliminaram-se, quase totalmente, as epidemias, transmitidas anteriormente por meio da contaminação da água. A suspensão dos serviços de água e esgoto representaria risco à saúde pública, na medida em que alguns dos integrantes da comunidade poderiam adquirir doenças, evitável por meio do tratamento de água e esgoto. ${ }^{23}$

Rizzatto Nunes, por seu turno, defende que o serviço público não pode ser interrompido. Afirma que a Lei n. 8.987/97 é "de constitucionalidade duvidosa" ao permitir o corte do fornecimento. Consigna que, salvo hipótese de ajuizamento de ação e demonstração que o consumidor está agindo de má-fé ao não pagar as contas, está vedado o corte do fornecimento. ${ }^{24}$

Cláudia Lima Marques, Herman Benjamin e Bruno Miragem, em obra coletiva, afirmam que a continuidade do serviço público essencial é direito do consumidor pessoa física "considerando a sua dignidade como pessoa humana." Para os autores, a interrupção dos serviços somente pode ocorrer excepcionalmente, quando não se constitui "forma de cobrança ou constrangimento, mas sim reflexo de um decisão judicial ou do fim não abusivo do direito. ${ }^{25}$

As divergências e controvérsias sobre o tema também são sensíveis na análise da jurisprudência. $\mathrm{O}$ assunto foi, exaustivamente, debatido no Superior Tribunal de Justiça. Inicialmente, focando os arts. 22 e 42 do CDC, entendeu-se pela ilegalidade do corte de fornecimento de água e de energia elétrica ${ }^{26} \mathrm{em}$ face do inadimplemento do consumidor. Citem-se, na sequência e apenas ilustrativamente, alguns julgados.

No REsp 201.112, Rel. Min. Garcia Vieira, julgado em 20 de abril de 1999, o STJ proferiu a seguinte ementa: "a Companhia Catarinense de Água e Saneamento negou-se a parcelar o débito do usuário e cortou-lhe o fornecimento de água, cometendo ato reprovável, desumano e ilegal. Ela é obrigada a fornecer água à população de maneira adequada, eficiente, segura e contínua, não expondo o consumidor ao ridículo e ao constrangimento."

Alguns meses depois, em 07 de dezembro de 1999, ao julgar o REsp 223.778, proferiu a seguinte decisão: “é defeso à concessionária de energia elétrica interromper o suprimento de força, no escopo de compelir o consumidor ao pagamento de tarifa em atraso. O exercício arbitrário das próprias razões não pode substituir a ação de cobrança."

No dia 05 de dezembro de 2000, no julgamento do REsp 122.812, o STJ, novamente, posicionou-se pela ilegalidade do corte de fornecimento de água em face do inadimplemento do consumidor. A ementa do julgado guarda o seguinte teor: "corte no fornecimento de água. Inadimplência do consumidor. Ilegalidade. 1. É ilegal a interrupção no fornecimento de energia elétrica, mesmo que inadimplente o consumidor, à vista das disposições do Código de Defesa do Consumidor que impedem seja o usuário exposto ao ridículo. 2. Deve a concessionária de serviço público utilizar-se dos meios próprios para receber os pagamentos em atrasos."

Todas as decisões do Superior Tribunal de Justiça que concluíram pela impossibilidade do corte do fornecimento de água analisaram a questão unicamente à luz do Código de Defesa do Consumidor, especialmente dos arts. 22 e 42. Não se dialogou com as disposições da Lei n. 8.987/97, que permitem o corte em face da inadimplência do usuário (consumidor).

Posteriormente, a partir de decisão proferida em 10 de dezembro de 2003, houve radical mudança do entendimento do STJ. Ao analisar o REsp 363.943, a Primeira Seção estabeleceu ser "lícito à concessionária interromper o fornecimento de energia elétrica, se, após aviso prévio, o consumidor de energia elétrica per-

23 SEGALLA, Alessandro. A suspensão do fornecimento de energia elétrica ao usuário inadimplente à luz da Constituição Federal. Revista de Direito do Consumidor. n. 37, Jan- Mar/2001. São Paulo: Revista dos Tribunais, p.139.

24 Ibid., p. 106.

25 Comentários ao Código de Defesa do Consumidor. São Paulo: Revista dos Tribunais, 2013, p. 646.

26 Embora o foco do artigo seja em relação ao fornecimento de água, o serviço público de fornecimento de energia elétrica também é essencial e se sujeita aos mesmos diplomas legais. 
manecer inadimplente no pagamento da respectiva conta (art. $6^{\circ}, \sqrt{\$} 3^{\circ}$, II, da Lei n. 8.987/95)". Embora a referência do julgado seja relativa ao fornecimento de energia elétrica, os mesmos argumentos e raciocínios foram utilizados para permitir o corte do fornecimento de água.

Vários outros julgados se sucederam com igual entendimento. Agora, o Código de Defesa do Consumidor (Lei n. 8.078/90) ficou para um segundo plano: especial atenção foi conferida à Lei n. 8.987/95. Ademais, pouca ou nenhuma importância se conferiu ao princípio constitucional da proteção à dignidade da pessoa humana $\left(\operatorname{art.} 1^{\circ}\right.$, III da CF).

Embora apresentem restrições quanto a débitos antigos, os acórdãos mais recentes reafirmam a possibilidade do corte do fornecimento de água em face de inadimplemento do consumidor, como se observa, ilustrativamente, da leitura da seguinte ementa: "1. Essa Corte Superior pacificou o entendimento de que não é lícito à concessionária interromper o fornecimento do serviço em razão de débito pretérito; o corte de água ou energia pressupõe o inadimplemento de dívida atual, relativa ao mês do consumo, sendo inviável a suspensão do abastecimento em razão de débitos antigos. (...) Agravo Regimental da AES Sul Distribuidora Gaúcha de Energia S/A desprovido. (AgRg no AREsp 239.749/RS, Rel. Min. Napoleão Nunes Maia Filho, julgado em 21/08/2014, DJe 01/09/2014). ${ }^{27}$

Observa-se, pelas divergências apresentadas, que tanto a doutrina como a jurisprudência tendem a assumir posições extremadas, ora para admitir, ora para vedar o corte. $\mathrm{O}$ diálogo das fontes, sob as luzes constitucionais, permite solução intermediária que, ao final, acaba por prestigiar as normas que estão em aparente conflito (Lei n. 8.078/90 e Lei n. 8.987/95), conferindo-se coerência interna ao ordenamento jurídico.

$\mathrm{Na}$ hipótese, ganha relevo a cláusula geral de proteção da dignidade da pessoa humana (art. $1^{\circ}$, III, da CF). No campo infraconstitucional, o Código de Defesa do Consumidor (Lei n. 8.078/90) e a Lei n. 8.987/95, que disciplina o regime de concessão e permissão dos serviços públicos (art. 175 da Constituição Federal).

De um lado, o CDC dispõe sobre a importância da dignidade humana, dos direitos existenciais (arts. $4^{\circ}$ e $6^{\circ}$ ). Determina, também, que os serviços essenciais devem ser contínuos (art. 22) e que, na cobrança de débitos, o consumidor "não será submetido a qualquer tipo de constrangimento" (art. 42). De outro, o \ $3^{\circ}$ do art. $6^{\circ}$ da Lei n. 8.987/95 estabelece que "não se caracteriza como descontinuidade do serviço a sua interrupção em situação de emergência ou após prévio aviso, quando: (...) II - por inadimplemento do usuário, considerado o interesse da coletividade."

Em síntese, a solução está em verificar se o corte importa, no caso concreto, em ofensa à dignidade da pessoa humana, ou seja, se pessoas físicas serão diretamente afetadas com a suspensão do fornecimento da água. O critério, ao contrário do que pode aparentar, não deve se pautar unicamente pelo fato de o consumidor ser pessoa jurídica ou física. Exemplifique-se com a sempre lembrada situação e graves consequências de um hospital (pessoa jurídica) que deixa de receber água. Sob outro enfoque, o contratante pode ser pessoa física, mas o fornecimento de água referir-se à unidade residencial que, há muito, está desabitada, não afetando, portanto, a qualidade (mínima) de vida de qualquer pessoa.

É importante perceber, para a solução das situações concretas, que o corte do fornecimento de água ou energia elétrica atinge, diretamente, interesses existenciais de todos os moradores da residência, invariavelmente crianças e idosos, consumidores hipervulneráveis, que não podem sofrer consequências tão drásticas em razão de fato atribuível a terceiro (titular da conta).

27 Na mesma linha, registre-se: “(...) A jurisprudência desta Corte é pacífica no sentido de ser devido o corte no fornecimento de água, após prévio aviso, ante a inadimplência de conta atual do usuário. Entretanto, na espécie, não houve o prévio aviso, segundo consignado no acórdão recorrido, motivo pelo qual o corte se deu de forma ilegal. Registre-se que para averiguar a existência de prévia comunicação feita pela concessionária, há necessidade de revolvimento de matéria probatória, o que é vedado nesta seara recursal, ante o óbice da Súmula 7/STJ. (...) (AgRg no AREsp 412.822/RJ, Rel. Ministro Mauro Campbell Marques, julgado em $19 / 11 / 2013$, DJe 25/11/2013) 
Há, ainda, outro argumento. O intérprete deve conferir coerência, a partir dos valores constitucionais, aos inúmeros diplomas (fontes) legais. Ora, no mínimo, deveria ser aplicado o mesmo prazo concedido pela Lei n. 9.870/99, relativa a anuidades escolares, que, mesmo em face de inadimplência, veda qualquer providência que impeça a conclusão do período escolar. ${ }^{28}$ Considerando-se a relevância do serviço prestado (educação), não se permite a interrupção imediata dos serviços por falta de pagamento da mensalidade. Sem qualquer propósito de estabelecer hierarquia entre valores, o fato é que o corte do fornecimento de água traz riscos à saúde humana (limpeza dos alimentos, higiene pessoal, etc.)

Não se sustenta que o inadimplemento relativo às contas de água não deva acarretar qualquer consequência para o devedor. O não pagamento ou atraso gera a incidência dos encargos próprios (juros de mora, multa, correção monetária). Ademais, o consumidor pode ter o nome inscrito em banco de dados de proteção ao crédito. ${ }^{29} \mathrm{O}$ que não pode haver é contrariedade a um minimo existencial (patrimônio mínimo personalíssimo) em face de vedação pelo ordenamento nacional, pois, como sintetiza Edson Fachin: "a pessoa natural, ao lado de atributos inerentes à condição humana, inalienáveis e insuscetíveis de apropriação, pode ser também, à luz do Direito Civil brasileiro contemporâneo, dotado de uma garantia patrimonial que integra sua esfera jurídica. Trata-se de um patrimônio mínimo mensurado consoante parâmetros elementares de uma vida digna e do qual não pode ser expropriada ou desapossada." ${ }^{30}$

Parte da dificuldade em lidar com a matéria é, justamente, a falta de sensibilidade de que os problemas jurídicos atuais, tanto pela variedade de situações fáticas - apenas aparentemente idênticas - como pela complexidade do ordenamento jurídico exigem um olhar "para o caso concreto", um balanceamento dos valores constitucionais em jogo, os quais indicarão a melhor interpretação.

No caso, o diálogo das fontes permite, a partir do enfoque constitucional, prestigiar ambas as fontes normativas, sem qualquer exclusão prévia. O projeto constitucional de proteção à dignidade da pessoa humana, confere, em concreto, relevância à continuidade do serviço (Lei n. 8.078/90) ou à possibilidade do corte (Lei n. 8.987/95), quando não houver ofensa, direta ou indireta, à dignidade da pessoa humana. ${ }^{31}$ É, em última análise, esta a preocupação dos votos vencidos no Superior Tribunal de Justiça, proferidos há dez anos. ${ }^{32}$

28 Interpretação conjugada dos artigos $5^{\circ}$ e $6^{\circ}$ Lei 9.870/99 permite concluir que, mesmo em face de inadimplência durante o semestre ou ano letivo, o estabelecimento de ensino não pode tomar qualquer medida que impeça a conclusão do período: “ Art. $5^{\circ}$ Os alunos já matriculados, salvo quando inadimplentes, terão direito à renovação das matrículas, observado o calendário escolar da instituição, o regimento da escola ou cláusula contratual. Art. $6^{\circ}$ São proibidas a suspensão de provas escolares, a retenção de documentos escolares ou a aplicação de quaisquer outras penalidades pedagógicas por motivo de inadimplemento, sujeitando-se o contratante, no que couber, às sanções legais e administrativas, compatíveis com o Código de Defesa do Consumidor, e com os arts. 177 e 1.092 do Código Civil Brasileiro, caso a inadimplência perdure por mais de noventa dias. \ $1^{\circ}$ Os estabelecimentos de ensino fundamental, médio e superior deverão expedir, a qualquer tempo, os documentos de transferência de seus alunos, independentemente de sua adimplência ou da adoção de procedimentos legais de cobranças judiciais."

29 O Código de Defesa do Consumidor em nenhum momento veda os registros de inadimplementos em entidades de proteção ao crédito relativos a serviços públicos - independentemente da sua essencialidade.

30 Estatuto jurídico do patrimônio mínimo. 2 ed. Rio de Janeiro: Renovar, 2006, p. 01.

31 Talvez, seja esta a coerência que está por trás de decisões aparentemente contraditórias, uma proferida em ação civil pública - na qual é mais problemática a análise de situações individuais - e outra proferida em ação ajuizada individualmente pelo consumidor. Nessa linha, o Tribunal de Justiça do Distrito Federal, em 11 de novembro de 1996, ao julgar AI 7.345/96, e o AI 7.110/96, sem qualquer referência ao CDC, entendeu que "sendo energia elétrica um bem essencial à vida das pessoas, na vida urbana, o seu fornecimento não pode ser suspenso, salvo em situações gravíssimas e sempre após decisão judicial transitado em julgado. O mesmo Tribunal, entretanto, ao julgar, em 12 de fevereiro de 2001, ação civil pública ajuizada pelo Ministério Público do Distrito Federal (Promotoria de Defesa do Consumidor), contra a CEB (Companhia Energética de Brasília) decidiu que "considerando o interesse da coletividade, a suspensão do fornecimento de energia elétrica, por inadimplência do usuário no pagamento da tarifa, não caracteriza descontinuidade, se precedida da comunicação ao usuário".

32 A propósito e unicamente a título ilustrativo, registre-se ementa do Resp. 684.442, julgado em 03 de fevereiro de 2005, que reflete o entendimento (minoritário) do Min. Luiz Fux: “(...) A 1ª Seção, no julgamento do RESP no 363.943/MG, assentou o entendimento de que é lícito à concessionária interromper o fornecimento de energia elétrica, se, após aviso prévio, o consumidor de energia elétrica permanecer inadimplente no pagamento da respectiva conta (Lei 8.987/95, art. $6^{\circ}$, \ $3^{\circ}$, II).3. Ademais, a $2^{\mathrm{a}}$ Turma desta Corte, no julgamento do RESP n ${ }^{\circ} 337.965 / \mathrm{MG}$ concluiu que o corte no fornecimento de água, em decorrência de mora, além de não malferir o Código do Consumidor, é permitido pela Lei no 8.987/95. 4. Não obstante, ressalvo o entendimento de que o corte do fornecimento de serviços essenciais - água e energia elétrica - como forma de compelir o usuário ao pagamento de tarifa ou multa, extrapola os limites da legalidade e afronta a cláusula 
Em conclusão, as posições extremadas da doutrina e da jurisprudência - tanto para permitir como para proibir o corte da água - não são as melhores. A solução está em, a partir do diálogo das fontes entre a Lei n. 8.078/90 e a Lei n. 9.897/95, com perspectiva constitucional da cláusula de proteção da dignidade da pessoa humana, optar pelo corte ou manutenção do serviço público.

\section{REFERÊNCIAS BIBLIOGRÁFICAS}

AZEVEDO, Fernando Costa de. A suspensão do fornecimento de serviço público essencial por inadimplemento do consumidor-usuário: argumentos doutrinários e entendimento jurisprudencial. Revista do Direito do Consumidor, v. 16, n. 62, abr./jun. 2007, São Paulo: Revista dos Tribunais.

BARROSO, Luis Roberto. A nova interpretação constitucional: ponderação, direitos fundamentais e relações privadas. Rio de Janeiro: Renovar, 2003.

BESSA, Leonardo Roscoe. Relação de Consumo e Aplicação do Código de Defesa do Consumidor. 2 ed. São Paulo: Revista dos Tribunais, 2009.

COMPARATO, Fábio Konder. A proteção do consumidor: importante capítulo do Direito econômico. Revista Forense, v. 255, ano 72, jul-set, Rio de Janeiro, 1976.

DENARI, Zelmo, Diálogo entre o Código de Defesa do Consumidor e o novo Código Civil: do "diálogo das fontes" no combate às cláusulas abusivas, Revista de Direito do Consumidor, São Paulo, n. 45, jan./ mar., 2003.

FACHIN, Luiz Edson. Estatuto jurídico do patrimônio mínimo. 2 ed. Rio de Janeiro: Renovar, 2006.

MARQUES, Cláudia Lima. Contratos no Código de Defesa do Consumidor. 5 ed. São Paulo: Revista dos Tribunais, 2011.

MARQUES, Claudia Lima. Diálogo entre o Código de Defesa do Consumidor e o novo Código Civil: do diálogo das fontes no combate às cláusulas abusivas. Revista de Direito do Consumidor, São Paulo, n. 45, jan./mar., 2003

MARQUES, Claudia Lima; BENJAMIM, Antônio Herman; MIRAGEM, Bruno. Comentários ao Código de Defesa do Consumidor. São Paulo: Revista dos Tribunais, 2013.

PERLINGIERI, Pietro. Perfis do direito civil: introdução ao direito civil constitucional. 2. ed., Rio de Janeiro: Renovar, 2002.

pétrea de respeito à dignidade humana, porquanto o cidadão se utiliza dos serviços públicos posto essenciais para a sua vida. 5. Hodiernamente, inviabiliza-se a aplicação da legislação infraconstitucional impermeável aos princípios constitucionais, dentre os quais sobressai o da dignidade da pessoa humana, que é um dos fundamentos da República, por isso que inaugura o texto constitucional, que revela o nosso ideário como nação. 6. In casu, o litígio não gravita em torno de uma empresa que necessita da energia para insumo, tampouco de pessoas jurídicas portentosas, mas de uma pessoa física miserável e desempregada, de sorte que a ótica tem que ser outra. Como afirmou o Ministro Francisco Peçanha Martins noutra ocasião, temos que enunciar o direito aplicável ao caso concreto, não o direito em tese. Forçoso, distinguir, em primeiro lugar, o inadimplemento perpetrado por uma pessoa jurídica portentosa e aquele inerente a uma pessoa física que está vivendo no limite da sobrevivência biológica. 7. Em segundo lugar, a Lei de Concessões estabelece que é possível o corte considerado o interesse da coletividade, que significa interditar o corte de energia de um hospital ou de uma universidade, bem como o de uma pessoa que não possui condições financeiras para pagar conta de luz de valor módico, máxime quando a concessionária tem os meios jurídicos legais da ação de cobrança. A responsabilidade patrimonial no direito brasileiro incide sobre o patrimônio do devedor e, nesse caso, está incidindo sobre a própria pessoa. 8. Outrossim, é voz corrente que o 'interesse da coletividade' refere-se aos municípios, às universidades, hospitais, onde se atingem interesses plurissubjetivos. 9. Destarte, mister analisar que as empresas concessionárias ressalvam evidentemente um percentual de inadimplemento na sua avaliação de perdas, e os fatos notórios não dependem de prova (notoria nom egent probationem), por isso que a empresa recebe mais do que experimenta inadimplementos. 10. Esses fatos conduzem a conclusão contrária à possibilidade de corte do fornecimento de serviços essenciais de pessoa física em situação de miserabilidade, em contrapartida ao corte de pessoa jurídica portentosa, que pode pagar e protela a prestação da sua obrigação, aproveitando-se dos meios judiciais cabíveis.10. Recurso Especial provido, ante a função uniformizadora desta Corte". 
ROCHA, Fábio Amorim da. A legalidade da suspensão do fornecimento de energia elétrica aos consumidores inadimplentes. Rio de Janeiro: Lumen Juris, 2004.

SEGALLA, Alessandro. A suspensão do fornecimento de energia elétrica ao usuário inadimplente à luz da Constituição Federal. Revista de Direito do Consumidor. n. 37, Jan- Mar/2001. São Paulo: Revista dos Tribunais.

SILVA, Elmo Rodrigues da. XI-009 - Um percurso pela história através da água: passado, presente, futuro. Disponível em: <http://www.bvsde.paho.org/bvsaidis/saneab/xi-009.pdf >.

TEPEDINO, Gustavo. A responsabilidade civil por acidentes de consumo na ótica Civil-constitucional, in Temas de Direito Civil. $3^{\text {a }}$ ed. Rio de Janeiro: Renovar, 2004.

UNIVERSIDADE DA ÁGUA. Água no planeta. Disponível em: < http://www.uniagua.org.br/publichtml/website/default.asp?tp=3\&pag=aguaplaneta.htm $>$.

VILAVERDE, Carolina, MUNIZ BAPTISTA, Lucas, SOARES, Jessica e SODRÉ, Raquel. O Fundo do Poço. Disponível em: <http://super.abril.com.br/crise-agua/ofundodopoco.shtml>. 
Para publicar na revista Brasileira de Políticas Públicas, acesse o endereço eletrônico www.rbpp.uniceub.br

Observe as normas de publicação, para facilitar e agilizar o trabalho de edição. 